\title{
Survey on factors affecting occupational accidents among construction industry workers in Khorramabad, Iran
}

\author{
Zamanian Z, $\mathrm{PhD}^{1}$, Hashemi H, $\mathrm{PhD}^{* 2}$, Azad P, BSc ${ }^{3}$, Mehri Y, MSc ${ }^{4}$, Kohnavard B, MSc ${ }^{4}$ \\ 1- Associate Prof., Research Center for Health Sciences, Shiraz University of Medical Sciences, Shiraz, Iran. \\ 2- Assistant Prof., Research Center for Health Sciences, Shiraz University of Medical Sciences, Shiraz, Iran. 3- BSc \\ Student Research Center for Health Sciences, Shiraz University of Medical Sciences, Shiraz, Iran.4- MSc Student \\ Research Center for Health Sciences, Shiraz University of Medical Sciences, Shiraz, Iran.
}

\begin{abstract}
Received: July 2015, Accepted: August 2015

Background: In spite of science and technology developments and their application in different industries, accidents occur in many work environments. Thus, this study was conducted in order to investigate factors affecting constructional accidents.

Materials and Methods: In this descriptive study, all workers who were injured in building construction during 2009-2010 and were registered in the Labor and Social Welfare Corporation were investigated. The data was collected through a checklist, and then, entered into SPSS software and analyzed using descriptive statistical methods.

Results: Most of the accidents (about 40\%) have occurred in the 24-29 year age group. Improvidence and nonuse of protective and safety instruments are the cause of $42 \%$ and $30 \%$ of accidents, respectively. The most injured parts of the body were the head (about 60\%) and hands (about 45\%). The least number of injured individuals was in the insulation and formatting sections (each one about 5\%). Most injured persons were hired for less than 1 month (40\%) and had job experience of less than 5 years (45\%). Approximately $0.5 \%$ of injured persons have died and $35 \%$ of events have caused bone fracture in different parts of the body.

Conclusions: The instructions related to protection, conforming to the related principles during work, and suggestion of solutions in order to prevent nonchalance, particularly for individuals with low job experience, will help to prevent accidents.
\end{abstract}

Keywords: Workers, Occupational Accidents, Construction Industry, Safety, Injuries

\section{Introduction}

Accidents due to work are events that occur during work and in the workplace and result in deadly or non-deadly injuries (1). These events are the third cause of death in the world and are introduced as one of the most important factors of hygienic, social, and economic danger in industrial and developing societies (2). The World Health Organization (WHO) refers to accidents due to work as an epidemic in public hygiene (3). Most of these events are preventable, and can result in disability, income reduction, and workers and their families' quality of life change, and also have considerable effects on the rate of countries' production and economics (4). Every year, thousands ${ }^{*}$ of individuals all over the world die because of these events. Constructional activities are considered to be the most dangerous activities in most countries (5). Identification of factors involved in the occurrence of these events is considered as a basic proceeding to control and reduce

\footnotetext{
* Corresponding author: Hassan Hashemi, Research Center for Health Sciences, Shiraz University of Medical Sciences, Shiraz, Iran.

Email: hashemi@hlth.mui.ac.ir
} 
danger and disabilities caused by them (6). Due to the relationship between these factors and the cultural, social, and economic contexts of each society, it is clear that these factors must be investigated in different societies and the results used to control and prevent them (7). In developing countries, the number of events that result in death is 3 or 4 times that in developed industrial countries (8). The direct and indirect costs caused by events result in million-dollar damages for employers every year. According to the European Agency for Health and Safety at Work estimation, 4.6 million job events take place in countries within the European Union (9). These events cause the loss of 146 million work hours, that is, almost $2.6 \%$ to $3.8 \%$ loss of total gross production of the European Union every year (9). Enormous costs are paid every year directly or indirectly due to lost active work force and lost work days (10). According to the report issued in 2011 by the Statistical Center of Iran, almost one third of the population is working in of the sections of industry, agriculture, and service (11). This shows that the majority of the valuable human force is subjected to job events. Constructional activities are recognized as one of the most dangerous jobs. Until now, there has been no investigation of constructional events in Khorramabad, Iran. However, some related studies have been conducted in countries that have acknowledged the importance of investigating occupational events. The current study was performed with the aim of offering valuable information and suitable solutions to reducing future occupational events. It was performed through identification of drawbacks due to constructional work accidents and studying some of the factors related to event occurrence. The collection of correct and exact information from all provinces is one of the effective factors in programming and prevention of future events. It is hoped that this study can help safety and hygiene managers and researchers to design and apply managerial principles in constructional events.

\section{Material and Methods}

This descriptive study was performed on constructional workers who had experienced occupational events during 2009-2010 and their accidents had been registered in the Labor and Social Welfare Corporation, Iran. The aimed population consisted of 220 constructional workers injured during the abovementioned years. Data were collected based on research goals and using a checklist. The research checklist included variables such as age, education level, job experience, event reason, and etcetera. Data were extracted from documents present in the Labor and Social Welfare Corporation, then analyzed through statistical methods and using SPSS software (version 16, SPSS Inc., Chicago, IL, USA).

\section{Results}

The accidents related to 220 injured constructional workers have been recorded during the abovementioned years. Figure 1 shows age distribution of investigated individuals. As can be seen, most events (about 40\%) have occurred among 24-29 year-old individuals. The highest frequency of injury was observed among illiterate individuals and the lowest frequency was related to bachelor's or higher education degrees. Moreover, the highest percentage of injured $(50 \%)$ was workers working in constructional activities, and the lowest percentage was related to individuals in the insulation section. Figure 2 illustrates that 
the highest percentage of injury was among individuals with less than 1 month job experience. Based on the findings of this research, the highest percentage of event occurrence is related to improvidence during work $(45 \%)$. Nonuse of personal protective instruments is the second most important factor and the cause of $40 \%$ of the abovementioned items. Figure 3 shows the frequency distribution of accidents based on the causes.

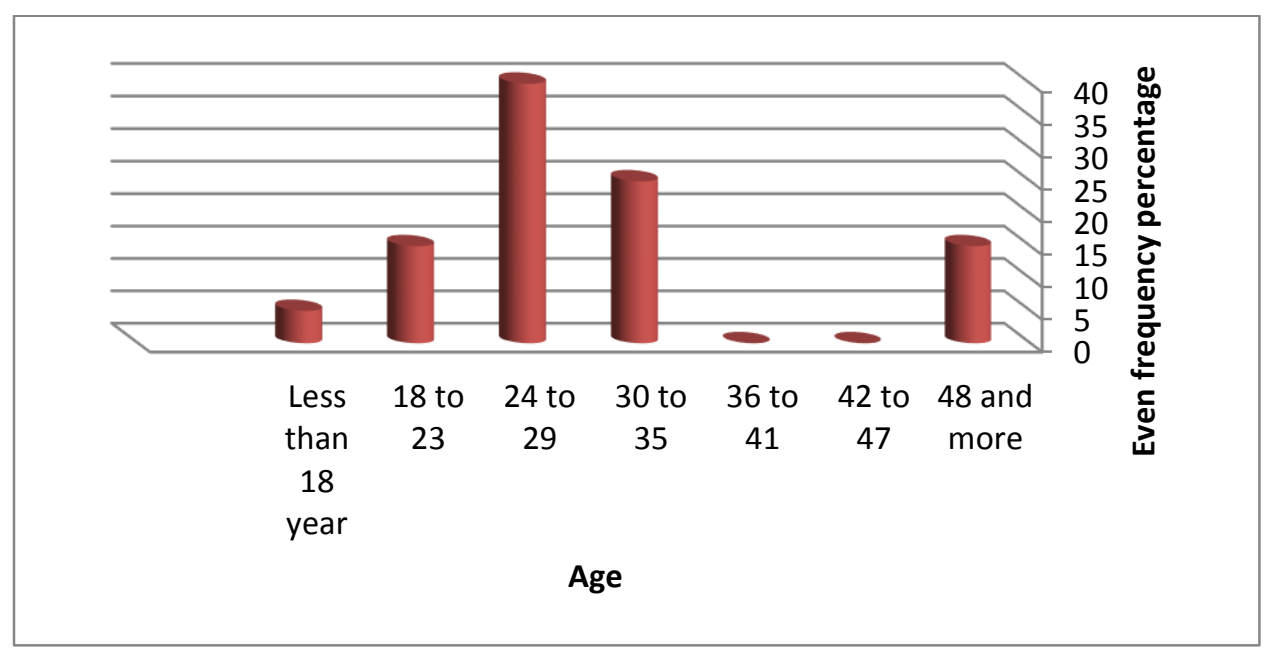

Figure1: Age distribution of accident frequency

Investigation of occupational accidents, their type, and severity is of grave importance. In the current study, the most injured part of the body was the head (60\%). Injuries to the head resulted from falling from a height because of nonuse of safeguard on the edge of a crag or an object dropping on the head due to lack of use of a helmet. The frequency of head and hand injuries were $45 \%$ and $13 \%$, respectively. Lack of equipment and skillful workers for assistance increases the effects of such accidents. Figure 4 shows the frequency distribution based on injured parts of the body.

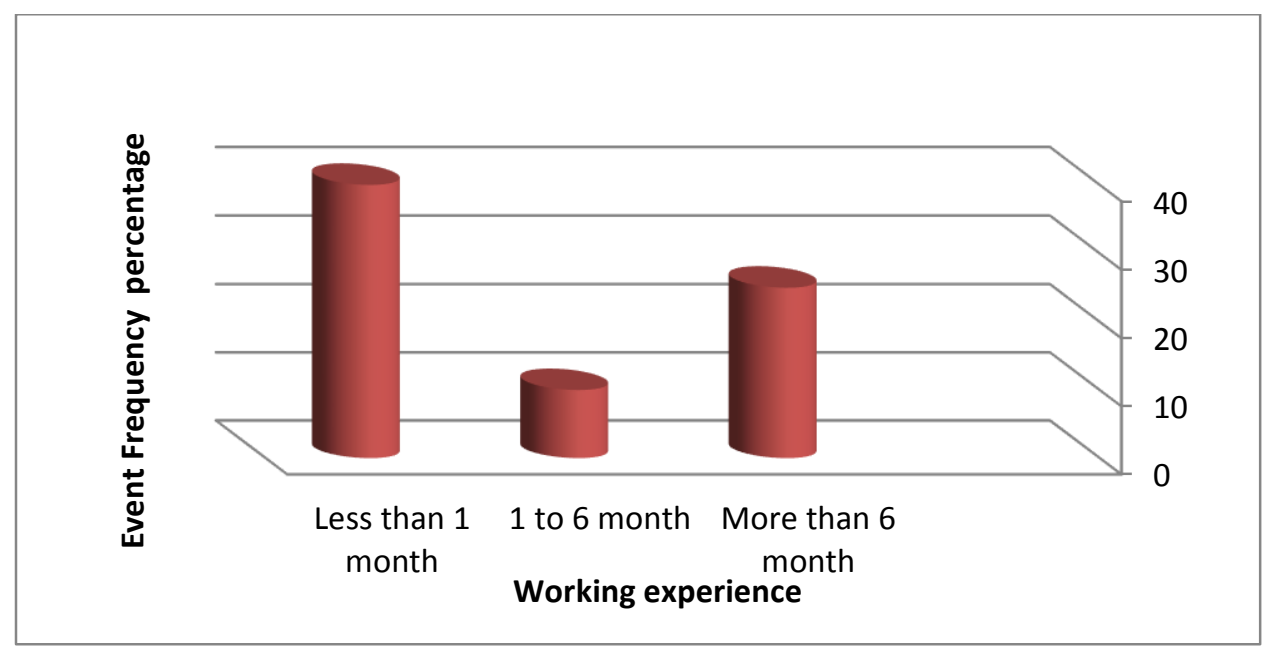

Figure 2: Frequency distribution based on the experience of the injured 


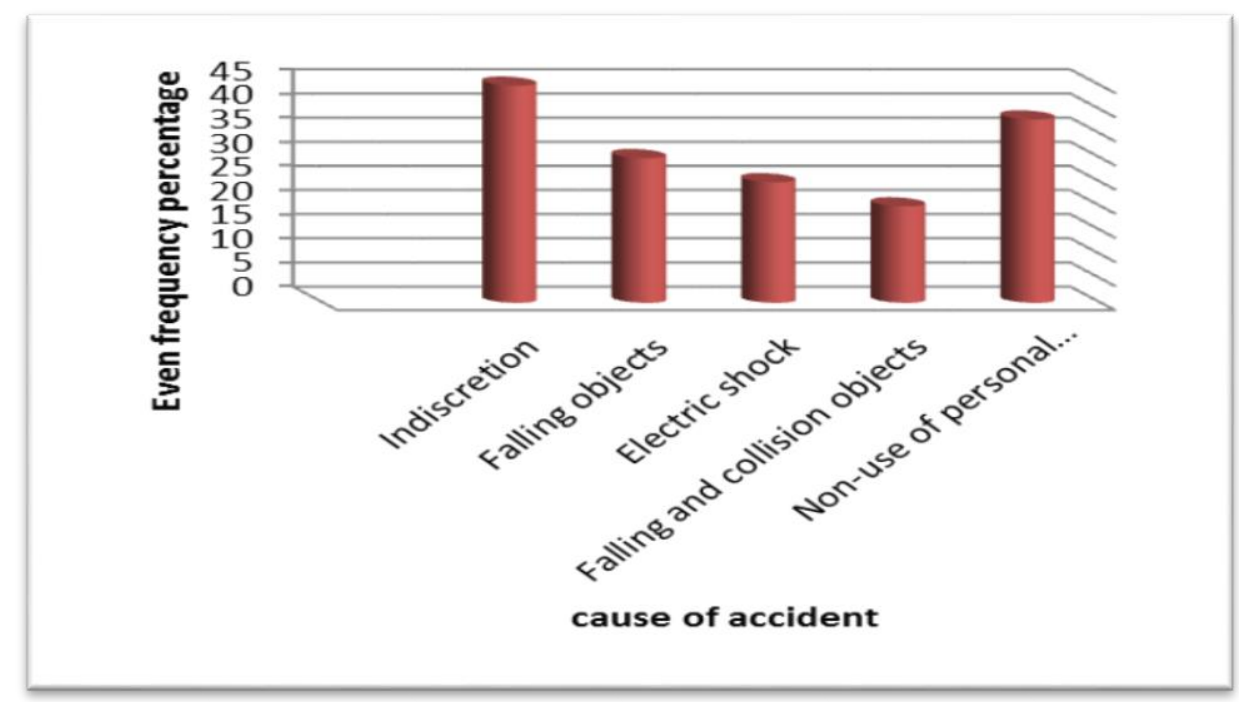

Figure 3: Frequency distribution based on the cause of accident

\section{Discussion}

The current study investigated some important underlying factors of 220 accidents due to constructional activities during 2 years in Khorramabad. The importance of the investigation of this group is due to the inclusion of some important events and their severe complications which resulted in individual referral and event recording. In other words, events of high significance with regard to hygienic and economic loses (individual health and lost active force) have been studied. The use of these results according to investigated factors was of great importance due to the possibility of offering regular plans to achieve the main goals. In order to do this, effective and underlying factors in investigated event occurrence can be divided into 2 dangerous groups. The first group consists of the known factors which are unchangeable like age. Although age cannot be changed, through the identification of the most at risk age group, it is possible to provide solutions in order to avoid the entrance of individuals in this age group into the mentioned activities.

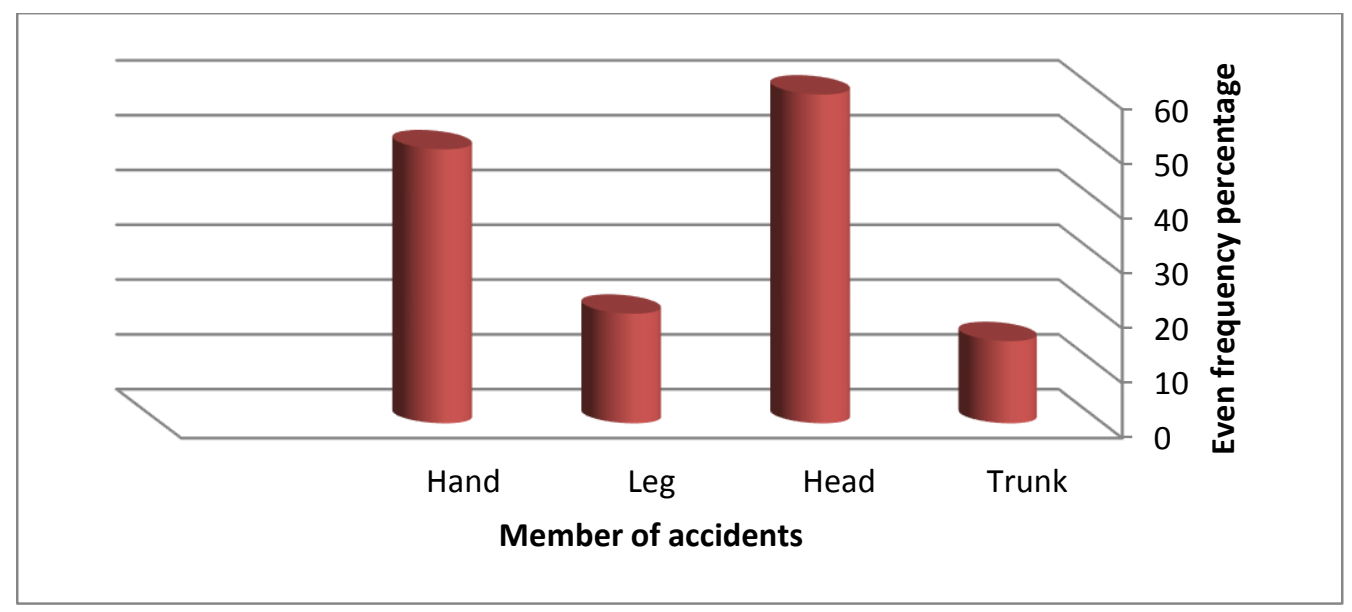

Figure 4: Frequency distribution based on injured parts of the body 
The second group consists of dangerous factors whose role can be omitted or their danger can be reduced. As an example, the effects of improvidence are important in event occurrence and this factor can be omitted through different methods or its effects can be minimized. The results show that about $40 \%$ of injured persons are 24 to 29 years old. This age group assigns a considerable rate of events to itself. If the prevalence of these events in this age group is taken into consideration through future researches, it may be possible to match the kind of constructional activities of this group with their age in order to reduce the rate of events. On the other hand, about $5 \%$ of these events occure in the less than 18 years age group; thus, further investigations are recommended in this regard. The meaningful statistical difference between single and married groups is predictable and these results are consistent with that of the studies by Shafieian (12) and Mohammad Fam (13). The results of this study show that the highest percentage of injured individuals have less than 1 month of job experience. In addition, the lowest percentage is related to those with more than 6 months of job experience. These results showed that the danger of job event occurrence is higher in groups with low job experiences (14). It can be inferred that like other jobs, higher job experience in constructional activities will increase individuals' familiarity with occupational dangers and reduce the likelihood of event occurrence. These experiences are gathered over the years and it is possible to transfer them to individuals with low job experience or individuals interested in certain jobs. As was predicted, there was a direct relationship between injured individuals and job experience. Therefore, it is important that individuals become stable in their job and change their job less, so that investment in their training will have long-lasting results. The research by Howitz and Mccall (2004) in Canada examined the amount of fiscal and health damage of constructional events (15). They showed that lack of caution is the reason for more than $45 \%$ of reported items and nonuse of protective instruments is the cause of $38 \%$ of accidents (15). Layana and Goat examined factors and determinants of constructional events and showed that workers trained in constructional activities are subject to less danger compared to those without training (16). In a study by Colak et al. on fatal damages of constructional activities, the cause of more than $16.8 \%$ of deaths due to these events was the lack of use of safety equipment (17). One of the limitations of this study was the lack of access to information on other occupations and industries. Thus, the consideration of this information is recommended in future studies.

\section{Conclusion}

It was concluded that professional hygiene training and more emphasis on meeting the present principles can prevent the occurrence of constructional accidents. The lack of use of safeguard in handling machines is still an important part of the occurrence of events. Therefore, it can be stated that in addition to training and encouragement of workers to use safety instruments, emphasis on meeting national job hygiene rules and attention to use of protection equipment by employers can considerably reduce the percentage of studied accidents.

\section{Acknowledgement}

The authors would like to thank Khorramabad Labor and Social Welfare 
Corporation and the Student Research Committee of Shiraz University of Medical Sciences, Iran, for their assistance in this research.

Conflict of Interest: None declared.

\section{References}

1. International Labor Organization. Safety in numbers: pointers for the global safety at work. Geneva: International Labour Office Geneva; 2003.

2. Dorman P. The economics of safety, health, and wellbeing at work: an overview. Geneva: International Labour Office Geneva; 2000.

3. Bakhtiyari M, Aghaie A, Delpisheh A, Akbarpour S, Zayeri F, Soori H, et al. An Epidemiologic Survey of Recorded JobRelated Accidents by Iranian Social Security Organization (2001-2005). Journal of Rafsanjan University of Medical Sciences 2012; 11(3):231-46.

4. Breslin FC, Smith P. Trial by fire: a multivariate examination of the relation between job tenure and work injuries. Occup Environ Med 2006; 63(1):27-32.

5. Ghods A, Alhani F, Anosheh M, Kahoei M. Epidemiology of occupational accidents in Semnan (2002-2006). Koomesh 2009; 10(2):95-100.

6. Solomon C, Poole J, Palmer KT, Coggon D. Non-fatal occupational injuries in British agriculture. Occup Environ Med 2007; 64(3):150-4..

7. DeLeire T, Levy H. Gender, Occupation Choice and the Risk of Death at Work. Cambridge: National Bureau of Economic Research (NBER); 2001 Nov. Report No: Working Paper 8574.
8. Soori H, Rahimi M, Mohseni H. Association between Job Stress and Work-Related Injuries: A case-control. Iranian Journal of Epidemiology 2006; 1(3-4):53-8.

9. Rikhardsson PM, Impgaard M. Corporate Cost of Occupational Accidents: An Activity-based Analysis. Accid Anal Prev 2004; 36(2):173-82.

10. Vazirinejad R, Esmaeili A, Kazemi M. Occupational accidents in construction industry among people referring to Labor and Social Affairs Office Rafsanjan, during 2000-2002. Journal of Rafsanjan University of Medical Sciences 2005; 4(4):326-31.

11. Iran. Statistical Centre of Iran. The summery results of survey on the permits issued by the nation's municipalities for construction of building. Tehran: winter 2011.

Available From: http://www.amar.org.ir/Portals/1/releases/Co nstruction-Permits-2010-winter.pdf

12. Loomis DP, Richardson DB, Wolf SH, Runyan $\mathrm{CW}$, Butts JD. Fatal occupational injuries in a southern state. Am J Epidemiol 1997; 145(12):1089-99.

13. Mohammadfam I, Moghimbeigi A. Evaluation of injuries among a manufacturing industry staff in Iran. J Res Health Sci 2009; 9(1):7-12.

14. Nevid JS, Rathus SA, Rubenstein H. Health in the new millenum. New York: Worth publisher; 1998. P 472-7.

15. Horwitz IB; McCall BP.Disabling and fatal occupational claim rates, risks, and costs in the oregon construction industry 1990-1997. J Occup Environ Hyg 2004; 1(10):688-98.

16. Layana E, Gost J. Analysis of determinants of work-related accidents in the construction industry. Ann Epidemiol 2004; 14(8):607-10

17. Bylund Po, Bjornstig Ulf. Occupational injuries and their long term concequences among mechanics and construction metal workers. Saf Sci 1998; 28(1):49-58. 